\title{
Prevalence of intestinal parasitic infections and associated risk factors among pregnant women attending antenatal care center at Felege Hiwot Referral Hospital, northwest Ethiopia
}

\author{
Adane Derso, Endalkachew Nibret ${ }^{*}$ and Abaineh Munshea
}

\begin{abstract}
Background: Parasitic infections affect tens of millions of pregnant women worldwide, and directly or indirectly lead to a spectrum of adverse maternal and fetal/placental effects. The objective of this study was to assess the prevalence of intestinal parasite infections and associated risk factors among pregnant women attending antenatal care center in Felege Hiwot Referral Hospital, Bahir Dar city, northwest Ethiopia.

Methods: A cross-sectional hospital based study was conducted from November 2013 to January 2014 among 384 pregnant women. Stool samples were examined for the presence of trophozoites, cysts, oocysts, and ova using direct, formal-ether sedimentation, and modified Ziehl-Neelsen techniques.

Results: An overall prevalence of $31.5 \%$ intestinal parasite infections was recorded. Eight different species of intestinal parasites were found: two protozoan and six helminth species. The highest prevalence was due to Giardia lamblia (13.3 \%) followed by Entamoeba histolytica/dispar (7.8\%), hookworm (5.5\%), Ascaris lumbricoides (2.9\%), Schistosoma mansoni (2.9\%), Strongyloides stercoralis (1.6\%), Taenia spp. (0.8\%), and Hymenolepis nana (0.3\%).
\end{abstract}

Conclusions: A relatively high prevalence of intestinal parasite infections was observed among pregnant women. Routine stool examination and provision of health education are required for early medical intervention that would affect the pregnant mothers and their foetuses.

Keywords: Intestinal parasites, Pregnant women, Bahir Dar, Ethiopia

\section{Background}

Intestinal parasitic infections constitute a global health burden causing clinical morbidity in 450 million people, many of these are women of reproductive age and children in developing countries [1]. Elevated intestinal parasitic infections have been recorded in developing countries because of poverty, low literacy rate, lack of safe drinking water, poor hygiene, malnutrition and hot and humid tropical climate $[2,3]$.

Tens of millions of pregnant women as one of the segments of the community are affected by parasitic infections

\footnotetext{
* Correspondence: endtg2002@yahoo.com

Department of Biology, College of Science, Bahir Dar University, P.O.Box 79, Bahir Dar, Ethiopia
}

\section{Biomed Central}

(c) 2016 The Author(s). Open Access This article is distributed under the terms of the Creative Commons Attribution 4.0 International License (http://creativecommons.org/licenses/by/4.0/), which permits unrestricted use, distribution, and reproduction in any medium, provided you give appropriate credit to the original author(s) and the source, provide a link to the Creative Commons license, and indicate if changes were made. The Creative Commons Public Domain Dedication waiver (http://creativecommons.org/publicdomain/zero/1.0/) applies to the data made available in this article, unless otherwise stated.

which directly or indirectly lead to a spectrum of adverse maternal and fetal/placental effects. Pregnant women often experience more severe infections than their non-pregnant counterparts [4]. Parasitic infection could occur at any stage of the three trimesters during pregnancy, but infection during the first trimester is associated with more severe fetal and placental consequences than those occurring later in pregnancy. Furthermore, the infection becomes more severe in women who are pregnant for the first time (primigravida) compared with other gravidae [5].

Intestinal parasitic infections (IPIs) are a major concern, mostly in developing countries, particularly in sub-Saharan Africa (SSA) [6]. Ethiopia has one of the lowest quality drinking water supply and latrine coverage in the world [7] 
and because of this and other risk factors, intestinal parasitic infections are the second most predominant causes of outpatient morbidity in the country. Several previous studies about parasitic infection conducted in Ethiopia have mainly focused on preschool children and school children [8-10]. The current study was necessitated to assess the prevalence of intestinal parasitic infection which is not well addressed among pregnant women of the country in general and those of Bahir Dar city in particular.

\section{Methods}

\section{Study design and study area}

A cross-sectional hospital based study was conducted from October 2013 to January 2014 so as to determine prevalence of intestinal parasitic infections and associated risk factors among pregnant women attending antenatal center at Felege Hiwot Referral Hospital, Bahir Dar, Ethiopia. Bahir Dar is the capital of the Amhara National Regional State in the Federal Democratic Republic of Ethiopia. It is located at $11^{\circ} 36^{\prime}$ latitude $\mathrm{N}$ and $37^{\circ} 23^{\prime}$ longitude $\mathrm{E}$ in north-western part of the country with an elevation of $1800 \mathrm{~m}$ above sea level and it is about $570 \mathrm{kms}$ away from Addis Ababa [Bahir Dar City Administration Office, General information about the city, unpublished]. According to Amhara Bureau of Finance and Economic Development (BOFED), population of Bahir Dar city was estimated to be 284,020. Among these, 149,202 of them are females [11]. The city has one referral hospital (Felege Hiwot Hospital), 10 health centers, 10 health posts and one family guidance association clinic and other private clinics [Bahir Dar City Health Bureau, Health infrastructure in Bahir Dar City, unpublished].

\section{Sample size determination}

In the estimation of the sample size, statistical formula for sample size calculation and previous work for prevalence of infectious diseases was considered as a basis [12]. Since prevalence of intestinal parasitic diseases in the study area was not known, the sample size of the proposed study was calculated using $50 \%$ prevalence, and a total of 384 pregnant women included in the study.

\section{Sampling techniques}

After obtaining written consent, a random sampling method was employed to include 384 study participants. Before sample collection, a brief explanation of the aims of study was given to volunteers and information was collected using a pre-structured questionnaire which contained questions related to socio-demographic characteristics, behavioral habits, and environmental conditions.

Each participant was provided with labeled screw capped stool container and informed on how to collect stool samples. Parts of the collected stool specimens were checked for trophozoites of protozoans and the remaining parts were preserved with $10 \%$ formalin. The collected stool samples were transported to Bahir Dar University Biomedical and Microbiology Laboratory and processed following the standard procedure using formol-ether concentration method for the detection of helminthes and for some of the protozoans [13] and Modified Ziehl-Neelsen technique for detection of Cryptosporidium spp [14].

\section{Source and study population}

All pregnant women who were attending antenatal clinic at Felege Hiwot Referral Hospital were considered as a source population while those who visited the same during sample collection period were considered as a study population.

\section{Inclusion and exclusion criteria}

Pregnant women who attended antenatal clinic at the study period and those who were willing to provide stool samples were included in the study and those who were not volunteers to give stool samples were excluded from the study.

\section{Data analysis}

Information recorded in the questionnaire and results collected from laboratory were checked for completeness and consistency and then coded and entered into computer. The compiled data were analyzed using Statistical Package for the Social Sciences (SPSS version 20.0). The magnitude of associations between intestinal parasitic infection and possible risk factors was determined using logistic regression and described in terms of odds ratio (OR) at $95 \%$ CI. After univariate logistic regression analysis, all variables with a $p$-value less than or equal to 0.3 were entered into multivariate logistic regression to identify independent risk factors for the occurrence of intestinal parasitic infection among pregnant women [15]. The raw data used for the statistical analysis of this study are shown in Additional file 1.

\section{Results}

Socio-demographic characteristics of study subjects

A total of 384 pregnant women were included in the study and a $100 \%$ response rate was obtained in filling out the questionnaires. The mean age of the study participants was $27.1 \pm 4.65$ year. The age of participants ranged from 18 to 44 years. Of the total study subjects, $358(93.2 \%)$ were married, 21 (5.5\%) were single and the rest $5(1.3 \%)$ were divorced. One hundred twenty two $(31.8 \%)$ women attended college or university and $116(30.2 \%)$ attended high school. One hundred three (26.8 \%) could write and read. Forty three (11.2\%) women were illiterate. Out of 384 participants, 44 $(11.5 \%)$ were rural residents and the rest $340(88.5 \%)$ were urban dwellers (Table 1). 
Table 1 Socio-demographic characteristics of pregnant women in Felege Hiwot Referral Hospital, Bahir Dar, Ethiopia (October 2013 - January 2014)

\begin{tabular}{|c|c|c|}
\hline Socio-demographic characteristics & Number of women & Percent \\
\hline \multicolumn{3}{|l|}{ Age (year) } \\
\hline $15-19$ & 5 & 1.3 \\
\hline $20-24$ & 108 & 28.1 \\
\hline $25-29$ & 176 & 45.8 \\
\hline $30-34$ & 61 & 15.9 \\
\hline $35-39$ & 27 & 7.0 \\
\hline $40-44$ & 7 & 1.8 \\
\hline \multicolumn{3}{|l|}{ Marital status } \\
\hline Married & 358 & 93.2 \\
\hline Single & 21 & 5.5 \\
\hline Divorced & 5 & 1.3 \\
\hline \multicolumn{3}{|l|}{ Education } \\
\hline Illiterate & 43 & 11.2 \\
\hline Writing and reading & 103 & 26.8 \\
\hline High school & 116 & 30.2 \\
\hline College/University and above & 122 & 31.8 \\
\hline \multicolumn{3}{|l|}{ Residence } \\
\hline Rural & 44 & 11.5 \\
\hline Urban & 340 & 88.5 \\
\hline \multicolumn{3}{|l|}{ Occupation } \\
\hline Governmental employee & 111 & 28.9 \\
\hline Private worker & 83 & 21.6 \\
\hline Housewives & 162 & 42.2 \\
\hline Daily laborers & 17 & 4.4 \\
\hline Others & 11 & 2.9 \\
\hline
\end{tabular}

\section{Medical history of study subjects}

Two hundred nine $(54.4 \%)$ pregnant women were in the third trimester (gestational age greater than 28 weeks), while 136 (35.4\%) were in their second trimester (between 13 and 28 weeks of gestation). Thirty nine (10.2\%) of the participants were in the first trimester (gestational age less than 13 weeks). Nearly half (43.5\%) of pregnant women were without a previous pregnancy. One hundred eighteen (30.7\%) participants had one child and the remaining 99 $(25.8 \%)$ women were pregnant for more than two times (Table 2).

\section{Prevalence of intestinal parasite infection across} environmental and sanitary conditions of study participants The results in Table 3 indicate the prevalence of intestinal parasitic infections with respective to environmental and sanitary conditions of the study participants. All the potential risk factors studied did not show statistical significant associations with intestinal parasitic infections $(p>0.05)$. Nevertheless, for example, in relation to behavioral factors, $31.3 \%(115 / 367)$ of studied pregnant women who had the habit of washing hands before eating were infected with intestinal parasites, in comparison to $35.3 \%(6 / 17)$ of women who did not wash their hands before meal. Additionally, $30.9 \%(116 / 376)$ were infected in group practicing hand washing after toilet, in comparison to $62.5 \%$ (5/8) women who did not wash their hands after toilet. With regard to feeding habits, $33.8 \%(77 / 228)$ of participants who ate raw/unwashed vegetables were infected, compared to $28.2 \%$ (44/ 156) of women who did not eat raw/unwashed vegetables. Regarding sanitary facility, $31.2 \%$ (116/372) of women who possessed toilet were infected with intestinal parasites, in comparison to $41.7 \%(5 / 12)$ who did not possess toilet in their houses.

\section{Overall and species specific prevalence of intestinal parasitic infection}

Intestinal parasitic infection was observed in 121 pregnant women and the overall prevalence was $31.5 \%$; out of which 81 cases $(21.1 \%)$ were caused by protozoans whereas 53 cases $(13.8 \%)$ were caused by helminthes. From those pregnant women who were infected, 13 cases were due to simultaneous infection by two different intestinal parasites. In this study, eight different species of intestinal parasites were identified, two protozoans, and six helminths species. Giardia lamblia was the most common protozoan parasite (13.3\%) followed by E.histolytica/dispar (7.8\%). Besides, helminthes identified in this study were Ascaris lumbricoides, hookworm, Strongyloides stercoralis, Schistosoma mansoni, Taenia species and Hymenolepis nana with their respective prevalence of $2.9 \%, 5.5 \%, 1.6 \%, 2.9 \%, 0.8 \%$, and $0.3 \%$.

\section{Univariate and multivariate analysis of risk factors in relation to prevalence of intestinal parasitic infections}

The univariate analysis results across socio-demographic, medical history, environmental, and sanitary factors are presented as crude odds ratios (COR) with $95 \%$ confidence intervals (Tables 2 and 3). However, none of sociodemographic, environmental, and behavioral factors were found to be independent explanatory variables in multivariate logistic regression analysis.

The univariate analysis (Table 2) of intestinal parasitic infection across socio-demographic and medical history revealed that the odds of infection with intestinal parasites were almost two times higher in illiterate than in those pregnant women whose educational level was at college or university $(\mathrm{COR}=1.65, p=0.44)$. It was also found that the odds of being infected with intestinal parasites in those who were married were almost two times higher $(\mathrm{COR}=1.92, p=0.39)$ than in those who were divorced or single. The odds of intestinal parasitic infection were increased by $43 \%$ in those whose monthly income was 
Table 2 Univariate analysis of intestinal parasitic infection across socio-demographic and medical history characteristics of pregnant women in Felege Hiwot Referral Hospital, Bahir Dar, Ethiopia (October, 2013 - January, 2014)

\begin{tabular}{|c|c|c|c|c|}
\hline \multirow[t]{2}{*}{ Characteristics } & \multirow[t]{2}{*}{ No examined (\%) } & Intestinal parasites & COR $(95 \%$ Cl) & $P$-value \\
\hline & & \multicolumn{2}{|l|}{ Positive (\%) } & \\
\hline \multicolumn{4}{|l|}{ Educational level } & 0.44 \\
\hline Illiterate & $43(11.2)$ & $18(41.9)$ & $1.65(0.81-3.39)$ & \\
\hline Writing and reading & $103(26.8)$ & $33(32.0)$ & $1.08(0.62-1.91)$ & \\
\hline High school & $116(30.2)$ & $33(28.4)$ & $0.91(0.52-1.59)$ & \\
\hline College/University and above & $122(31.8)$ & $37(30.3)$ & 1 & \\
\hline \multicolumn{4}{|l|}{ Marital status } & 0.39 \\
\hline Married & $358(93.2)$ & $116(33.2)$ & $1.92(0.21-17.35)$ & \\
\hline Single & $21(5.5)$ & $4(17.1)$ & $0.94(.08-10.88)$ & \\
\hline Divorced & $5(1.3)$ & $1(16.7)$ & 1 & \\
\hline \multicolumn{5}{|l|}{ Monthly income (Ethiopian Birr) } \\
\hline Less than 500 & $74(19.3)$ & $29(39.2)$ & $1.43(0.83-2.47)$ & 0.20 \\
\hline $500-1000$ & $88(22.9)$ & $23(26.1)$ & $0.77(0.45-1.37)$ & \\
\hline Above 1000 & $222(57.8)$ & $69(31.1)$ & 1 & \\
\hline \multicolumn{4}{|l|}{ Occupation } & 0.89 \\
\hline Governmental employee & $111(28.9)$ & $36(32.4)$ & 1 & \\
\hline Private work & $83(21.6)$ & $24(28.9)$ & $0.85(0.46-1.57)$ & \\
\hline Housewives & $162(42.2)$ & $54(33.3)$ & $1.04(0.62-1.74)$ & \\
\hline Daily laborers & $17(4.4)$ & $4(23.5)$ & $0.64(0.20-2.11)$ & \\
\hline Others & $11(2.9)$ & $3(27.3)$ & $0.80(0.20-3.12$ & \\
\hline \multicolumn{4}{|l|}{ Residence } & 0.70 \\
\hline Urban & $340(88.5)$ & $106(31.2)$ & 1 & \\
\hline Rural & 44 (11.5) & $15(34.1)$ & $1.14(0.59-2.22)$ & \\
\hline \multicolumn{4}{|l|}{ Parity } & 0.62 \\
\hline Primegravidae & $167(43.5)$ & $57(34.1)$ & $1.25(0.73-2.14)$ & \\
\hline Bigravidae & 118 (30.7) & 35 (29.7) & $1.02(0.57-1.83)$ & \\
\hline Multigravidae & $99(25.8)$ & $29(29.3)$ & 1 & \\
\hline \multicolumn{4}{|l|}{ Trimester } & 0.62 \\
\hline $1 s t$ & $39(10.2)$ & $11(28.2)$ & $0.91(0.43-1.94)$ & \\
\hline 2nd & 136 (35.4) & 47 (34.6) & $1.22(0.77-1.94)$ & \\
\hline $3 r d$ & $209(54.4)$ & $63(30.1)$ & 1 & \\
\hline \multicolumn{4}{|l|}{ Age (year) } & 0.64 \\
\hline $15-19$ & $5(1.3)$ & $1(20)$ & $0.63(0.04-9.65)$ & \\
\hline $20-24$ & $108(28.1)$ & 33 (30.6) & $1.10(0.20-5.96)$ & \\
\hline $25-29$ & $176(45.8)$ & $53(30.1)$ & $1.08(0.20-5.73)$ & \\
\hline $30-34$ & $61(15.9)$ & $25(41.0)$ & $1.74(0.31-9.67)$ & \\
\hline $35-39$ & $27(7.0)$ & $7(25.9)$ & $0.88(0.14-5.58)$ & \\
\hline $40-44$ & $7(1.8)$ & $2(28.6)$ & 1 & \\
\hline
\end{tabular}

below 500 Ethiopian Birr compared to those whose monthly income was above 1000 Ethiopian Birr. Regarding residential area of the women, the odds for intestinal parasitic infection were increased by $14 \%$ in those who lived in rural areas compared to those who lived in urban areas. The odds for intestinal parasitic infection were increased by $25 \%$ in primegravidae women compared to multigravidae women. The odds of intestinal parasitic infection were increased by $22 \%$ in the second trimester women compared to those in 
Table 3 Univariate analysis of intestinal parasitic infections in relation across hygiene and environmental factors of pregnant women in Felege Hiwot Referral Hospital, Bahir Dar (November 2013 - January 2014)

\begin{tabular}{|c|c|c|c|c|}
\hline \multirow[t]{2}{*}{ Characteristics } & \multirow[t]{2}{*}{ No examined (\%) } & Intestinal parasites & COR $(95 \% \mathrm{Cl})$ & $P$-value \\
\hline & & \multicolumn{2}{|l|}{ Positive (\%) } & \\
\hline Hand washing before meal & & & & 0.73 \\
\hline Yes & 367 (95.6) & $115(31.3)$ & 1 & \\
\hline No & $17(4.4)$ & $6(35.3)$ & $1.19(0.43-3.31)$ & \\
\hline Raw/unwashed vegetables & & & & 0.25 \\
\hline Yes & $228(59.4)$ & 77 (33.8) & $1.29(0.83-2.02)$ & \\
\hline No & $156(40.6)$ & $44(28.2)$ & 1 & \\
\hline Hand washing after toilet & & & & 0.07 \\
\hline Yes & $376(97.9)$ & $116(30.9)$ & 1 & \\
\hline No & $8(2.1)$ & $5(62.5)$ & $3.74(0.88-15.89)$ & \\
\hline Toilet presence & & & & 0.45 \\
\hline Yes & $372(96.9)$ & $116(31.2)$ & 1 & \\
\hline No & $12(3.1)$ & $5(41.7)$ & $1.58(0.49-5.07)$ & \\
\hline Soil contact & & & & 0.35 \\
\hline Yes & $87(22.7)$ & 31 (35.6) & $1.27(0.77-2.11)$ & \\
\hline No & $297(77.3)$ & $90(30.3)$ & 1 & \\
\hline Water drinking source & & & & 0.93 \\
\hline Tap water & $358(93.2)$ & $113(31.6)$ & 1 & \\
\hline Well & $26(6.8)$ & $8(30.8)$ & $0.96(0.41-2.28)$ & \\
\hline Soil eating & & & & 0.55 \\
\hline Yes & $30(7.8)$ & $8(26.7)$ & $0.78(0.34-1.79)$ & \\
\hline No & $354(92.2)$ & $113(31.9)$ & 1 & \\
\hline
\end{tabular}

their third trimester of pregnancy. Regarding the age of the women, the odds for intestinal parasitic infection were almost two times higher $(\mathrm{COR}=1.74, p=0.64)$ in those whose age was between 30 and 34 years than in those whose age was between 40 and 44 years.

The output of statistical analysis provided in Table 3 shows intestinal parasitic infections across hygiene and environmental factors. As hand washing practice before meal was decreased by one, the odds of intestinal parasitic infection were increased by $19 \%$. As eating raw/ unwashed vegetables was increased by one at every meal, the odds of intestinal parasitic infection were increased by $29 \%$. Additionally, the statistical analysis showed that the odds of infection were about four times higher $(\mathrm{COR}=3.74, p=0.07)$ in pregnant women who had no habit of hand washing after toilet than those who had the habit of washing their hands after toilet. It was showed that the odds of infection with intestinal parasites were almost two times higher in pregnant women who had no toilet $(\mathrm{COR}=1.58, p=0.45)$ in comparison to women who had access to toilet. It was also found that as the soil contact was increased by one, the odds for intestinal parasitic infection were increased by $27 \%$.

\section{Discussion}

Estimating the burden of a disease requires adequate epidemiological information [16]. The present study was therefore focused on determining the prevalence of intestinal infections and associated risk factors among pregnant women. Surprisingly, high prevalence of intestinal parasites (31.5\%) was recorded among pregnant women attending Felege Hiwot Referral Hospital, Bahir Dar city, Ethiopia. Such a relatively high prevalence of intestinal parasitic infection observed in the present study might be because of environmental pollution of parasite cysts, ova, and larvae and this could be one of the reasons why there is permanent transmission of parasites among humans in endemic regions. Intestinal protozoa are known to be transmitted by the fecal-oral route and their transmission involves the ingestion of food or water contaminated with cysts. The ova of soil-transmitted helminthes such as $A$. lumbricoides, $H$. nana could be ingested from contaminated fingers, water, food or soil. Hookworm and S. stercoralis infections are acquired when the larvae penetrate exposed human skin from contaminated soil. S. mansoni infection is acquired when the larval stage, cercaria, penetrates the human body from contaminated water bodies. In case of Taenia spp, consumption of raw or inadequately cooked, infected beef 
(in case of T. saginata) or pork (in case of T. solium) introduces the larvae into the human intestinal tract where they mature into adult worms [17].

The prevalence of intestinal parasites identified in the present study (31.5\%) was higher than $14.3 \%$ which was reported among pregnant women at Azezo Health Center of Gondar town, northwest Ethiopia [18] and those of $17.6 \%$ and $13 \%$ reported from Ghana [19] and Senegal [20], respectively. However, our finding was lower than the findings of other similar types of studies reported from Nigeria (43.4 \%) [21], Kenya (76.2 \%) [22], Gabon (65 \%) [23], and Venezuela (73.9\%) [24]. Difference in findings among various studies could be explained by variations in geography, socio-economic conditions, and cultural practices of the population under consideration. The specific type of study subjects, the methods employed for stool examination, and the time of study may have also contributed to the variation. Furthermore, variation in the prevalence of geophagy (soil eating) among different communities may be one of the reasons for observed varied prevalence of intestinal parasitic infections. Geophagy is thought by many as adaptive behavior to correct nutritional deficiencies, for example, iron deficiency [25]. In other study, however, it has been shown that pregnant women eat soils for varied reasons. Some pregnant women have preference for texture of soil while others for its taste [26]. Nevertheless, this soil eating habit may be a risk factor for soil-transmitted helminthic infection. For example, a study by Kawai et al. [27] showed that the prevalence of geophagy was associated with A. lumbricoides infection, not with hookworm and S. stercoralis infections. It is known that infection by most parasites decrease reproduction in animals including humans. But, a recent study among women of Tsimane, Bolivia, revealed an interesting result in which infection with $A$. lumbricoides was associated with earlier first births and shortened interbirth intervals, whereas infection with hookworm was associated with delayed first pregnancy and extended interbirth intervals [28].

Prevalence of double infections in the current study accounted $3.38 \%$. However, this double infection rate was relatively lower than previously reported prevalence [29]. All of the socio-demographic variables considered in the present study were found to be non-significant predictors of intestinal parasitic infections among pregnant women.

In the current finding, all environmental and sanitary risk factors do not seem to play major roles in the occurrence of intestinal parasitic infections in the studied pregnant women. However, research done in Teda town at Teda Health Center, Gondar, Ethiopia showed that the variables age, absence of toilet, and hand washing after toilet to be significantly associated with the occurrence of intestinal parasitic infections [30].

\section{Conclusions}

The overall prevalence of intestinal parasitic infection was relatively high. The proportion of intestinal protozoal infection was higher than that of helminthic infection. Giardia lamblia and hookworm were the most dominant parasites from protozoans and helminthes, respectively. None of the variables included in the present study as potential risk factors showed statistical significant associations with intestinal parasitic infections.

\section{Limitations of the study}

Compared to PCR diagnostic technique, modified Ziehl-Neelsen method is less sensitive for the detection of Cryptosporidium spp., and this might be one of the reasons why Cryptosporidium spp could not be detected in the study subjects. Moreover, light microscopy fails to differentiate between E. histolytica and E. dispar and also between $T$. saginata and $T$. solium.

\section{Additional file}

Additional file 1: Data used for statistical analysis of the present study. Sheet 1 of xls data shows the data used for statistical analysis of the present study whereas the second sheet (sheet 2) shows the summary of statistical analysis of some of the socio-demographic variables studied. (XLS $156 \mathrm{~kb}$ )

\section{Abbreviations}

BOFED: Amhara Bureau of Finance and Economic Development; COR: Crude odds ratio; IPIs: Intestinal parasitic infections; OR: Odds ratio; PCR: Polymerase chain reaction; SPSS: Statistical package for the social sciences; SSA: sub-Saharan Africa

\section{Acknowledgements}

We are grateful to laboratory technicians, nurses, medical doctors, and study participants for cooperation up to the final research work.

\section{Funding}

This research was funded by College of Science, Bahir Dar University, Grant number: BDU/RCS/Sc 32/2007. The funding body was not involved in the design of the study, collection, analysis, and interpretation of data, nor in writing the manuscript.

\section{Availability of data and materials}

Questionnaire used for this study is available upon request to the corresponding author. The raw data used for the statistical analysis is indicated as "Additional file 1."

\section{Authors' contributions}

EN and $A M$ conceived the idea for this study. $A D, E N$, and $A M$ participated in the design and conduct of the study. AD, EN, and AM were responsible for the accuracy of the data. $A D$ and EN drafted the manuscript. $A D$ and $E N$ guarantee the statistical analysis. AD, EN, and AM interpreted the findings. All authors read and approved the final manuscript.

\section{Authors' information}

During the study period, AD was an MSc student in Biomedical Sciences at Biology Department, Bahir Dar University. Dr Endalkachew Nibret was an Associate Professor of Biomedical Sciences at Biology Department, Bahir Dar University. Dr Abaineh Munshea was an Assistant Professor of Biomedical

Sciences at Biology Department, Bahir Dar University.

Competing interests

The authors declare that they have no competing interests.

Consent for publication

Not applicable. 


\section{Ethics approval and consent to participate}

The study was approved by ethical committee of College of Science, Bahir Dar University (ethical consideration number: SCPGRC/117/2006) and permission was also obtained from Felege Hiwot Referral Hospital. An informed consent was obtained from all participants before testing and commencing the study. A code number was given to each study subject. The diagnosis results were remained confidential and necessary treatments were given by physicians.

Received: 17 September 2016 Accepted: 20 September 2016 Published online: 30 September 2016

\section{References}

1. Quihui L, Valencia ME, Crompton DTE, Phillips S, Hagan P, Morales G, Diaz-Camacho SP. Role of the employment status and education of mothers in the prevalence of intestinal parasitic infections in Mexican rural schoolchildren. BMC Public Health. 2006;6:225.

2. Pillai DR, Kain KC. Common intestinal parasites. Curr Treat Opt Infect Dis. 2003;5:207-17.

3. Bethony J, Brooker S, Albonico M, Geiger SM, Loukas A, Diemert D, Hotez PJ. Soil-transmitted helminth infections: ascariasis, trichuriasis, and hookworm. Lancet. 2006:367:1521-32

4. Whitty CJM, Edmonds S, Mutabingwa TK. Malaria in pregnancy. BJOG. 2005; 112:1189-95.

5. Muhangi L, Woodburn P, Omara M, Omoding N, Kizito D, Mpairwe H, Nabulime J, Ameke C, Morison LA, Elliott AM. Associations between mild to moderate anaemia in pregnancy and helminth, malaria and HIV infection in Entebbe, Uganda. Trans R Soc Trop Med Hyg. 2007;101:899-907.

6. Harhay MO, Horton J, Olliaro PL. Epidemiology and control of human gastrointestinal parasites in children. Expert Rev Anti Infect Ther. 2010;8:219-34.

7. Kumie A, Ali A. An overview of environmental health status in Ethiopia with particular emphasis to its organization, drinking water and sanitation: a literature survey. Ethiop J Health Dev. 2005;19:89-103.

8. Legesse M, Erko B. Prevalence of intestinal parasites among schoolchildren in rural area close to the southeast of Lake Langano, Ethiopia. Ethiop J Health Dev. 2004;18:116-20.

9. Alebie G, Erko B, Aemero M, Petros B. Epidemiological study on Schistosoma mansoni infection in Sanja area, Amhara region, Ethiopia. Parasit Vectors. 2014;7:15.

10. Abera A, Nibret E. Prevalence of gastrointestinal helminthic infections and associated risk factors among schoolchildren in Tilili town, northwest Ethiopia. Asian Pac J Trop Med. 2014;7:525-30

11. BOFED. Unpublished data of Bureau of finance and economic development. Bahir Dar: Amhara National Regional State; 2014.

12. Naing $L$, Winn T, Rusil BN. Practical issues in calculating sample size for prevalence studies. Arch Orofacial Sci. 2006;1:9-14

13. Cheesbrough M. District laboratory practice in tropical countries. Part2. Cambridge: Cambridge University Press; 2006.

14. Adegbola RA, Demba E, Deveer G, Todd F. Cryptosporidium infection in Gambian children less than 5 years of age. Am J Trop Med Hyg. 1994;97:103-7.

15. Victoria CG, Huttly SR, Fuchs SC, Olinto MTA. The role of conceptual frameworks in epidemiological analysis: a hierarchical approach. Int J Epidemiol. 1997;26:224-7.

16. Pullan RL, Smith IL, Jasrasaria R, Brooker SJ. Global numbers of infection and disease burden of soil transmitted helminth infections in 2010. Parasite \& Vectors. 2014;7:37.

17. Roberts LS, Janovy J. Gerald D Schmidt \& Larry S. Roberts' foundations of parasitology. 8th ed. New York: McGraw-Hill Companies, Inc; 2009.

18. Alem M, Enawgaw B, Gelaw A, Kena T, Seid M, Olkeba Y. Prevalence of anemia and associated risk factors among pregnant women attending antenatal care in Azezo Health Center Gondar town, Northwest Ethiopia. J Inter Discipl Histopathol. 2013;1:137-44.

19. Baidoo SE, Tay SCK, Obiri-Danso K, Abruquah HH. Intestinal helminth infection and anaemia during pregnancy: A community based study in Ghana. J Bacteriol. 2010;2:9-13.

20. Binetou CS, Robert TJ. Iron deficiency is a major risk factor for anemia among pregnant women in Senegal. Afr J Health Sci. 2011;18:1-2.

21. Egwunyenga AO, Ajayi JA, Nmorsi OPG, Duhlinska-Popova DD. Plasmodium/ intestinal helminth co-infections among pregnant Nigerian women. Mem Inst Oswaldo Cruz, Rio de Janeiro. 2011;96:1055-9.
22. van Eijk AM, Lindblade KA, Odhiambo F, Peterson E, Rosen DH, Karanja D, Ayisi JG, Shi YP, Adazu K, Slutsker L. Geohelminth infections among pregnant women in rural western Kenya; a cross-sectional study. PLoS Negl Trop Dis. 2009;3:e370.

23. Adegnika AA, Ramharter M, Agnandji ST, Ngoa UA, Issifou S, Yazdanbahksh M, Kremsner PG. Epidemiology of parasitic co-infections during pregnancy in Lambare'ne', Gabon. Trop Med Int Health. 2010;15:1204-9.

24. Rodriguez-Morales AJ, Barbella RA, Case C, Arria M, Ravelo M, Perez H, Urdaneta O, Gervasio G, Rubio N, Maldonado A, Aguilera Y, Viloria A, Blanco JJ, Colina M, Hernandez E, Araujo E, Cabaniel G, Benitez J, Rifakis P. Intestinal parasitic infections among pregnant women in Venezuela. Infect Dis Obstet Gynecol. 2006;2006:1-5.

25. Abrahams PW, Parsons JA. Geophagy in the tropics: a literature review. The Geogr J. 1998;162:63-72.

26. George G, Abiodun A. Physiological effects of geophagy (soil eating) with reference to iron. Nutritional status in pregnant women: a study in selected antenatal clinics in KSD municipal area of the Eastern Cape, South Africa, 3rd International conference on biology, environment and chemistry. IPCBEE 2012, Vol. 46. Singapore: IACSIT Press; 2012

27. Kawai K, Saathoff E, Antelman G, Msamanga G, Fawzi WW. Geophagy (soil-eating) in relation to anemia and helminth infection among HIV-infected pregnant women in Tanzania. Am J Trop Med Hyg. 2009:80:36-43.

28. Blackwell AD, Tamayo MA, Beheim B, Trumble BC, Stieglitz J, Hooper PL, Martin M, Kaplan H, Gurven M. Helminth infection, fecundity, and age of first pregnancy in women. Science. 2015;350:970-2.

29. Getachew M, Tafess K, Zeynudin A, Yewhalaw D. Prevalence soil transmitted helminthiasis and malaria co-infection among pregnant women and risk factors in Gilgel Gibe Dam area, Southwest Ethiopia. BMC Res Notes. 2013;6:263.

30. Abate A, Kibret B, Bekalu E, Abera S, Teklu T, Yalew A, Endris M, Worku L, Tekeste $Z$. Cross-sectional study on the prevalence of intestinal parasites and associated risk factors in Teda Health Centre, Northwest Ethiopia. ISRN Parasitol. 2013;2013:1-5.

\section{Submit your next manuscript to BioMed Central and we will help you at every step:}

- We accept pre-submission inquiries

- Our selector tool helps you to find the most relevant journal

- We provide round the clock customer support

- Convenient online submission

- Thorough peer review

- Inclusion in PubMed and all major indexing services

- Maximum visibility for your research

Submit your manuscript at www.biomedcentral.com/submit
) Biomed Central 